\title{
Análises químicas em flocos de quinoa: caracterização para a utilização em produtos alimentícios
}

\author{
Chemical analysis of quinoa flakes: characterization for use in food products
}

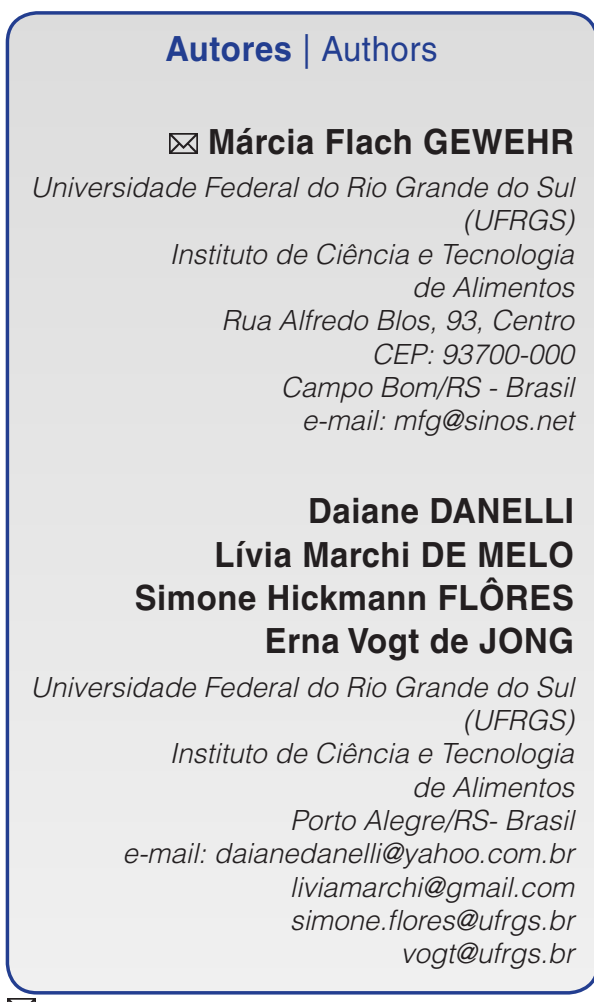

Autor Correspondente / Corresponding Author

Recebido / Received: 08/02/2010 Aprovado / Approved: 11/07/2012 Publicado / Published: dez./2012

\section{Resumo}

A quinoa é um pseudocereal, cultivada principalmente na região andina. Tem sido descrita como uma importante fonte de proteínas de alta digestibilidade e apresenta composição equilibrada de aminoácidos e alto teor de lipídios, principalmente ácidos graxos insaturados. Atrai a atenção dos pesquisadores por causa da sua superior qualidade nutricional em relação a outros cereais. A caracterização química dos flocos de quinoa foi feita por meio da determinação de umidade, cinzas, lipídios, composição de ácidos graxos, proteínas, aminograma, fibras e suas frações, tocoferóis, sódio, cálcio, ferro, zinco e fósforo. Os flocos apresentaram altos teores de proteína, fibras, fósforo e ferro, quando comparados com o que a legislação vigente determina. Houve equilíbrio no balanceamento de aminoácidos e entre fibras solúveis e insolúveis. Na composição de ácidos graxos, destacou-se o oleico, sendo este imprescindível à saúde. Pelos resultados obtidos nas análises, deve-se explorar o uso desse pseudocereal em produtos alimentícios com a finalidade de agregar valor nutricional e produzir alimentos que contribuam para o bem-estar e a saúde do indivíduo.

Palavras-chave: Flocos de quinoa; Composição química; Aminoácidos; Ácidos graxos; Tocoferóis; Minerais.

\section{Summary}

Quinoa is a pseudocereal planted mainly in the Andes region. It has been described as an important source of highly digestible proteins with a balanced amino acid composition, and with a high level of lipids, mainly unsaturated fatty acids. It has attracted the attention of researchers due to its superior nutritional quality when compared to other cereals. The chemical characterization of the quinoa flakes was carried out by determining the moisture content, ash, lipids, fatty acid composition, proteins, amino-gram, fibers and their fractions, tocopherols, sodium, calcium, iron, zinc and phosphorous. The flakes presented high levels of protein, fibers, phosphorous and iron, when compared to current legislation. There was equilibrium in the amino acid balance and between the soluble and insoluble fibers. In the fatty acid composition, oleic acid, which is indispensable for health, stood out. From the results obtained in the analysis, one should explore the use of this pseudocereal in food products, aiming at adding nutritional value and producing foods which contribute to the well-being and health of the person.

Key words: Quinoa flakes; Chemical composition; Amino acids; Fatty acids; Tocopherols; Minerals. 


\section{Introdução}

A Chenopodium quinoa é um pseudocereal, também conhecida como pseudo-oleoginosa, cultivada em Bolívia, Peru, Estados Unidos, Equador, algumas áreas da Colômbia, Chile e Argentina (LEÓN e ROSELL, 2007), além de estar difundida na América do Sul, cujo principal campo de uso está na alimentação, sendo todas as partes da planta utilizadas (MADL et al., 2006). Os incas reconheceram há muito tempo seu alto valor nutricional (LEÓN e ROSELL, 2007); eles acreditavam que a quinoa tinha propriedades medicinais (DOGAN e KARWE, 2003).

Este pseudocereal atraiu atenção para a suplementação da alimentação, porque as suas sementes contêm $12 \%$ de proteína, com equilíbrio de aminoácidos (KONISHI et al., 2004). É considerada como fonte de minerais e vitaminas do complexo B (riboflavina), quando comparada com aveia, arroz e milho (KOZIOL, 1992). Além disso, possui quantidades significativas de flavonoides e ácidos fenólicos. Os derivados fenólicos são agentes antimicrobianos naturais e apresentam-se como bons antioxidantes, reduzindo a quantidade de radicais livres formados e promovendo atividades quelantes de metais. Por sua vez, os polifenóis são benéficos à saúde, prevenindo enfermidades, como câncer e doenças cardiovasculares (DOGAN e KARWE, 2003).

O uso deste pseudocereal aumenta cada vez mais, sendo utilizado tanto para a alimentação saudável como para dietas especiais de pessoas celíacas, uma vez que a quinoa não possui glúten (GORINSTEIN et al., 2008; LEÓN e ROSELL, 2007). A quinoa pode ser inclusa em pães, sopas, tortas, torrones, chocolates, massas, saladas e alimentos infantis, pois as agroindústrias processam os grãos em flocos e farinha (BHARGAVA et al., 2006; LEÓN e ROSELL, 2007; NSIMBA et al., 2008). Tanto o processamento dos grãos quanto os fatores genéticos, climáticos e do solo podem interferir na composição nutricional. Dessa forma, torna-se importante analisar a composição dos flocos de quinoa.

\section{Material e métodos}

\subsection{Amostra de quinoa}

A amostra de flocos de quinoa (Chenopodium Quinoa Willdenow) originários do Peru foi adquirida da Empresa Obst Trade Comércio Exterior Ltda, Porto Alegre-RS. Segundo a empresa, os grãos foram previamente lavados e posteriormente laminados. Ao chegar ao Instituto de Ciência e Tecnologia de Alimentos (ICTA), os flocos foram transferidos para recipientes de vidro e armazenados sob refrigeração a $8{ }^{\circ} \mathrm{C}$.

\subsection{Análise dos flocos de quinoa}

\subsubsection{Composição centesimal}

Todas as análises foram feitas em triplicata no Laboratório de Bromatologia do ICTA/UFRGS e os valores apresentados como médias. A concentração de proteína foi determinada pelo método semimicro-Kjeldahl (CUNNIFF, 1995; IAL, 1985) e o fator de conversão do nitrogênio para proteína foi de 6,25 (KOZIOL, 1992). As quantidades de lipídios, fibra (total, solúvel e insolúvel), cinzas e umidade foram mensuradas de acordo com Cunniff (1995) e Normas Analíticas do Instituto Adolfo Lutz (IAL, 1985). O total de carboidrato foi determinado por diferença (BRASIL, 2003).

\subsubsection{Composição em ácidos graxos}

O perfil lipídico foi determinado no CEPPA, da Universidade Federal do Paraná, de acordo com o método Horwitz (2000), Firestone (1998), Hartman e Lago (1973) e Holland et al. (1998).

\subsubsection{Composição em aminoácidos}

A determinação da composição de aminoácidos foi realizada no Centro de Química da Faculdade de Medicina de Ribeirão Preto (USP, Ribeirão Preto, Brasil). A amostra foi desengordurada e hidrolisada com hidróxido de lítio, para medida de triptofano (LUCAS e SOTELO, 1980), e com ácido clorídrico, para determinação dos demais aminoácidos. A análise foi realizada por cromatografia iônica com derivação pós-cromatográfica por ninidrina, como descrito por Spackman et al. (1963), utilizando-se analisador automatizado (ALONSO e HIRS, 1968), para determinação do perfil aminoacídico.

\subsubsection{Concentração de tocoferóis}

A quantificação de tocoferóis ( $\alpha, \beta, \gamma$ e $\delta$-tocoferóis) foi realizada no Centro de Qualidade Analítica (CQA, São Paulo, Brasil), de acordo com método Horwitz (2005), que consiste na saponificação das vitaminas lipossolúveis e na análise por cromatografia líquida de alta eficiência (HPLC).

\subsubsection{Concentração de minerais}

O cálcio, o ferro e o zinco foram determinados por meio do método de espectroscopia de absorção de chama, enquanto o sódio, por fotometria de chama, e o fósforo, por espectrometria, conforme Horwitz (1980).

\section{Resultados e discussão}

A Tabela 1 apresenta os resultados da análise dos flocos de quinoa (em bases úmida e seca) juntamente com os dados de literatura para a composição do grão, da farinha e do grão tostado de quinoa. 
Análises químicas em flocos de quinoa: caracterização para a utilização em produtos alimentícios GEWEHR, M. F. et al.

Tabela 1. Composição química dos flocos de quinoa comparada com dados da literatura da composição do grão, da farinha e do grão tostado de quinoa.

\begin{tabular}{|c|c|c|c|c|c|}
\hline $\begin{array}{l}\text { Informações gerais e } \\
\text { composição química }\end{array}$ & \multicolumn{2}{|c|}{$\begin{array}{l}\text { Flocos de } \\
\text { quinoa }\end{array}$} & $\begin{array}{l}\text { Grão de } \\
\text { quinoa }^{1}\end{array}$ & $\begin{array}{l}\text { Farinha de } \\
\text { quinoa }^{2}\end{array}$ & $\begin{array}{c}\text { Grão tostado de } \\
\text { quinoa }^{3}\end{array}$ \\
\hline Origem & \multicolumn{2}{|c|}{ Peru } & - & Colorado & Brasil \\
\hline \multirow[t]{2}{*}{ Processamento } & $\begin{array}{l}\text { Lavagem e lt } \\
\text { temperatura in }\end{array}$ & $\begin{array}{l}\text { aminação à } \\
\text { ferior a } 30^{\circ} \mathrm{C} .\end{array}$ & - & $\begin{array}{l}\text { Remoção do pericarpo } \\
\text { e saponina por } \\
\text { equipamento. Moagem. }\end{array}$ & $\begin{array}{c}\text { Torrefação a } 100^{\circ} \mathrm{C} \\
\text { por } 3 \text { horas }\end{array}$ \\
\hline & (\% peso úmido) & (\% peso seco) & (\% peso seco) & (\% peso seco) & (\% peso seco) \\
\hline Umidade & 11,93 & - & - & - & - \\
\hline Carboidrato & 60,95 & 69,21 & - & 65,94 & 76 \\
\hline Amido & - & - & $53,0-85,7$ & 63,02 & - \\
\hline Proteína & 11,73 & 13,32 & $11,0-15,0$ & 16,92 & 11,04 \\
\hline Lipídios & 4,88 & 5,54 & $3,2-10,7$ & 4,99 & 7 \\
\hline Fibra alimentar total & 8,65 & 9,82 & $1,1-10,7$ & 9,65 & 1,54 \\
\hline Fibra alimentar solúvel & 4,80 & 5,45 & - & 1,3 & - \\
\hline Fibra alimentar insolúvel & 3,85 & 4,37 & - & 8,35 & - \\
\hline Cinzas & 1,86 & 2,11 & $2,1-10,7$ & 2,49 & 2,21 \\
\hline
\end{tabular}

Fonte: 'León e Rosell (2007); ${ }^{2}$ Ranhotra et al. (1993); ${ }^{3}$ Shumacher (2008).

Os teores de macronutrientes determinados, no presente trabalho, nos flocos de quinoa foram similares aos valores informados por Ranhotra et al. (1993) para a farinha de quinoa. Entretanto, o equilíbrio nas frações de fibra (solúveis e insolúveis) desses dois grupos foi bastante diferente, agregando funcionalidades opostas. Sabe-se que fatores genéticos e climáticos interferem diretamente na composição nutricional da quinoa e, de acordo com Koziol (1992), variedades de quinoa do Equador possuem mais gordura e proteína em relação às andinas. Além disso, os princípios nutritivos dos cereais não se distribuem homogeneamente. O processamento e a manufatura dos grãos tornam mais evidentes essas diferenças, e as indústrias aproveitam certas partes para conseguir a disponibilidade de matéria-prima mais adequada à elaboração de diferentes alimentos (SALINAS, 2002).

Dessa forma, os resultados dos flocos de quinoa divergiram daqueles encontrados na literatura para o grão tostado, em razão da maior quantidade de fibras e da menor quantidade de carboidratos. Contrapondo-se às comparações realizadas entre os diferentes tipos de quinoa com seus respectivos processamentos, verificou-se que todos esses grupos assemelham-se na faixa de teores de nutrientes mencionada para o grão de quinoa por León e Rosell (2007). Sugere-se que houve certa similaridade na faixa de teores de proteínas e variações nos teores de lipídios e/ou fibras e/ou cinzas e/ou carboidratos.

Em função da elevada quantidade de proteínas nos flocos de quinoa, 11,73\% (base úmida), estes podem ser considerados alimentos com alto teor proteico (BRASIL, 1998a) e são, comumente, utilizados na preparação de alimentos como substitutos parciais ou totais de cereais, uma vez que apresentam quantidades de proteínas, em peso seco, semelhantes à aveia (11,6\%), ao trigo (10,5\%) e ao arroz (9,1\%) (REPO-CARRASCO et al., 2003).

A quinoa destaca-se como uma importante fonte de proteínas para os seres humanos, por causa de sua digestibilidade e sua composição equilibrada dos aminoácidos essenciais. Em experimentos com ratos verificou-se, através de análise do coeficiente de eficácia protéica, digestibilidade verdadeira e balanço de nitrogênio, semelhança entre a eficiência da proteína da quinoa e a do leite (RANHOTRA et al., 1993), sendo este resultado também apresentado em estudo com humanos utilizando tanto semente como farinha do pseudocereal (KOZIOL, 1992).

Os flocos analisados apresentaram adequado equilíbrio de aminoácidos essenciais, quando comparado com a indicação da FAO ano 1985 (WHO, 2002), para adultos (Tabela 2).

A proteína dos flocos de quinoa não pode ser considerada de elevado valor biológico, pois apresentou quantidades inferiores às necessidades do indivíduo de triptofano e isoleucina, mas possui teores elevados de lisina, geralmente o aminoácido limitante nos cereais, e histidina, quando comparada com arroz, trigo, aveia (Tabela 2) (WRIGHT et al., 2002; KOZIOL, 1992).

Resultados similares foram descritos por Bhargava et al. (2006), que também mencionaram o elevado teor de metionina no aminograma $(0,4-1,0 \%)$, condizente com os encontrados nos flocos de quinoa.

A quinoa pode apresentar como primeiro aminoácido limitante a tirosina ou a fenilalanina (IMPROTA e KELLEMS, 
Tabela 2. Composição de aminoácidos essenciais dos flocos de quinoa (média e desvio padrão), requerimento de aminoácidos e valor biológico da proteína. Comparação da composição de aminoácidos essenciais analisados nos flocos de quinoa com dados da literatura para cereais e caseína.

\begin{tabular}{|c|c|c|c|c|c|c|c|}
\hline $\begin{array}{c}\text { Aminoácido } \\
\text { (mg aminoácidos/ } \\
\text { g proteína) }\end{array}$ & $\begin{array}{c}\text { Flocos de } \\
\text { quinoa }\end{array}$ & $\begin{array}{c}\text { Requerimento } \\
\text { de aminoácido } \\
\text { para adulto }^{1}\end{array}$ & $\begin{array}{c}\text { Perfil de aminoácidos } \\
\text { essenciais (teórico) } \\
\text { para proteína de elevado } \\
\text { valor biológico }{ }^{2}\end{array}$ & Arroz $^{3}$ & Trigo $^{3}$ & Aveia $^{4}$ & Caseína $^{5}$ \\
\hline Histidina* & $33,33 \pm 1,27(1,23)$ & 15 & 17 & 21 & 20 & 21 & 27 \\
\hline Isoleucina & $41,10 \pm 0,48(0,87)$ & 15 & 42 & 41 & 42 & 38 & 47 \\
\hline Leucina & $76,76 \pm 0,09(0,81)$ & 21 & 70 & 82 & 68 & 73 & 95 \\
\hline Lisina & $59,19 \pm 0,30(0,76)$ & 18 & 51 & 38 & 26 & 37 & 78 \\
\hline Metionina + Cistina & $29,52 \pm 0,35(0,89)$ & 20 & 26 & 36 & 37 & - & 33 \\
\hline Fenilalanina + Tirosina & $83,19 \pm 0,51(0,82)$ & 21 & 73 & 105 & 82 & - & 102 \\
\hline Treonina & $49,35 \pm 0,92(1,12)$ & 11 & 35 & 38 & 28 & 33 & 44 \\
\hline Triptofano & $6,59 \pm 0,06(0,47)$ & 5 & 11 & 11 & 12 & 13 & 14 \\
\hline Valina & $48,99 \pm 0,45(0,77)$ & 15 & 48 & 61 & 44 & 51 & 64 \\
\hline
\end{tabular}

Fonte: ${ }^{1} \mathrm{FAO}, 1985$ (WHO, 2002); ${ }^{2}$ Sgarbieri (1987); ${ }^{3}$ Wright et al. (2002); ${ }^{4}$ León e Rosell (2007); ${ }^{5}$ Brasil (1998b) *Essencial para crianças. Valores em parênteses indicam a relação do conteúdo de aminoácidos presentes entre os flocos de quinoa e a caseína (padrão).

2001). Nos flocos, esse aminoácido foi o triptofano, divergindo de Comai et al. (2007), que comentaram a alta concentração de triptofano no pseudocereal, geralmente o segundo aminoácido limitante nos cereais. No entanto, a complementação da quinoa com legumes ou cereais (aveia, trigo e arroz) supre o requerimento desse aminoácido em relação à proteína padrão, a caseína (Tabela 2).

Os flocos de quinoa também apresentaram composição equilibrada de aminoácidos não essenciais, dentre os quais, arginina, ácido glutâmico, ácido aspártico e alanina - na forma livre -, que podem desempenhar um papel importante na formação de cor e aroma durante a torrefação (DINI et al., 2005). Em razão do alto teor e da qualidade da proteína dos flocos de quinoa, esta pode ter uma participação, apesar de pequena, na atividade antioxidante global, tendo antioxidantes eficazes na inibição da peroxidação lipídica e agindo como quelantes de radicais livres (GORINSTEIN et al., 2007).

Em relação ao teor de lipídios, na quinoa este pode variar na faixa de 2 a 10\%, dependendo dos métodos de cultivo (KOZIOL, 1992).

A Tabela 3 apresenta o teor de lipídios totais e a composição de ácidos graxos dos flocos de quinoa analisados e do arroz (literatura).

Os flocos de quinoa apresentaram 4,88\% de lipídios, em comparação com 2,90\% do arroz (Tabela 3). Esses dois cereais continham quantidades maiores de ácidos graxos insaturados do que saturados. Essa relação torna-se importante, pois os ácidos graxos saturados elevam a colesterolemia por reduzirem receptores hepáticos e inibirem a remoção plasmática de LDL, enquanto os ácidos graxos insaturados exercem efeitos protetores, podendo reduzir os níveis sanguíneos de LDL e triglicérides (SANTOS e AQUINO, 2008).

Koziol (1992) e Repo-Carrasco et al. (2003) mencionaram a composição semelhante do óleo de quinoa com o de soja, ressaltando sua importância econômica, uma vez que contém $82,71 \%$ de ácidos graxos insaturados e $11 \%$ de saturados, sendo predominante 0 ácido palmítico. Os ácidos insaturados, compostos por ácido linoleico, oleico e $\alpha$-linolênico, aparecem nas concentrações de 52,3\%, 23\% e 8,1\% de ácidos graxos totais, respectivamente.

Os flocos de quinoa analisados contêm 26,43\% de ácidos graxos saturados, predominantemente o palmítico, e 66,6\% de ácidos graxos insaturados, representados por 46,72\% de monoinsaturados e 19,88\% de poli-insaturados. Os ácidos graxos linoleico, oleico e $\alpha$-linolênico representam 16,8\%,42,63\% e 0,61\%, respectivamente, em ácidos graxos totais, divergindo de Koziol (1992) e Repo-Carrasco (2003), que mencionaram maior concentração do ácido linoleico seguido do oleico, no óleo. Possivelmente, tenha havido interferência tanto do método de cultivo e do método de análise, quanto do processamento desse pseudocereal.

O ácido oleico, predominante nos flocos de quinoa, segundo Angelis (2001), pode atuar prevenindo o reumatismo reumatoide, por causa da alteração da produção de mediadores de respostas inflamatórias.

Embora haja elevada concentração de ácidos graxos insaturados, os flocos de quinoa são estáveis em função da sua elevada quantidade de tocoferóis, principalmente $\alpha$ e $\gamma$-tocoferol (BHARGAVA et al., 2006; REPO-CARRASCO et al., 2003). O $\alpha$-tocoferol apresenta-se como vitamina $E$, podendo variar de 2 a 5 mg.100 g-1 (LEÓN e ROSELL, 2007), com maior 
Análises químicas em flocos de quinoa: caracterização para a utilização em produtos alimentícios

GEWEHR, M. F. et al.

conteúdo do que o arroz $\left(0,18 \mathrm{mg} .100 \mathrm{~g}^{-1}\right)$ e o trigo $\left(1,15 \mathrm{mg} .100 \mathrm{~g}^{-1}\right)(\mathrm{KOZIOL}, 1992)$. Na Tabela 4, a qual apresenta a quantidade de tocoferóis encontrados nas análises dos flocos de quinoa, pode-se verificar a concordância dos resultados com as observações mencionadas das citações.

O poder antioxidante do $\delta$-tocoferol é maior do que o $\gamma$, seguido pelo $\beta$ e o $\alpha$. Os tocoferóis atuam como antioxidantes no nível da membrana das células e protegem dos danos causados aos ácidos graxos das membranas pelos radicais livres. Assim, estes componentes parecem ser particularmente importantes na prevenção da aterosclerose, porque agem como substâncias redutoras que evitam a oxidação dos ácidos graxos insaturados, com formação de radicais livres e produtos de degradação de peróxidos, que podem danificar os tecidos (SGARBIERI, 1987).

Os flocos de quinoa podem ser considerados alimentos com alto teor de fibras por conter mais de $6 \mathrm{~g}$ de fibra. $100 \mathrm{~g}^{-1}$ de produto e 8,65\% de fibras (base úmida) (Tabela 1) (BRASIL, 1998a). Os cereais, como arroz e farinha de trigo, apresentam quantidades inferiores de fibras (3,5\% e 2,4\%, respectivamente) (LEÓN e ROSELL, 2007).

Dietas ricas em fibras estão associadas à prevenção da obesidade (DINI et al., 2005). Em virtude do equilíbrio entre as fibras solúveis ( $4,80 \%$ base úmida) e insolúveis (3,85\% base úmida) nos flocos de quinoa, elas podem contribuir para redução dos níveis plasmáticos de colesterol e diluição dos carcinogênicos potenciais, bem como manter o menor tempo de contato desses compostos com as paredes intestinais (PIMENTEL et al., 2005).

A quinoa também apresenta diversidade em minerais: fósforo (384 mg.100 g ${ }^{-1}$ ), cálcio (149 mg.100 g ${ }^{-1}$ ), magnésio (250 mg. $100 \mathrm{~g}^{-1}$ ), zinco (4,4 mg. $\left.100 \mathrm{~g}^{-1}\right)$, ferro (13,2 mg. $100 \mathrm{~g} \mathrm{~g}^{-1}$ ) e potássio (927 mg.100 g ${ }^{-1}$ ) (KOZIOL, 1992). O conteúdo de minerais na semente de quinoa é aproximadamente duas vezes maior do que nos outros cereais (SCHOENLECHNER et al., 2008).

Os resultados encontrados nos flocos de quinoa (Tabela 5) divergem dos encontrados por Koziol (1992), pois se observou menor conteúdo de minerais, com exceção do fósforo. O teor deste último mineral equivale ao encontrado no arroz, na aveia e no trigo (Tabela 5).

Os flocos de quinoa foram elaborados pelo processo de laminação e, de acordo com Konishi et al. (2004), o processamento abrasivo da semente pode resultar em decréscimo no conteúdo de cálcio. Além disso, condições climáticas e do solo influenciam a composição de minerais (KARYOTIS et al., 2003).

Os flocos de quinoa analisados podem ser considerados alimentos de alto teor de fósforo (mínimo
Tabela 3. Lipídios totais e composição de ácidos graxos dos flocos de quinoa e do arroz.

\begin{tabular}{lcc}
\hline & Flocos de quinoa & Arroz $^{1}$ \\
\hline Gordura Total & 4,88 & 2,90 \\
(g.100 $\mathbf{~ g}^{-1}$ - base úmida) & & \\
Composição dos ácidos graxos & $\left(\mathbf{g . 1 0 0} \mathbf{~ g}^{-1}\right.$ - base úmida) \\
Saturados & 1,29 & 0,60 \\
Palmítico & 0,85 & 0,50 \\
$\quad$ Esteárico & 0,10 & 0,05 \\
Monoinsaturados & 2,28 & 1,10 \\
Oleico & 2,08 & 1,05 \\
Poli-insaturados & 0,97 & 1,00 \\
$\quad$ Linolênico & 0,03 & 0,04 \\
Linoleico & 0,82 & 1,00 \\
\hline
\end{tabular}

Fonte: 'León e Rosell (2007).

Tabela 4. Quantidade e tipos de tocoferóis encontrados nos flocos de quinoa.

\begin{tabular}{cc} 
Tocoferóis (mg.100 $\mathbf{~ g}^{\mathbf{- 1}}$ ) & Flocos de quinoa \\
$\alpha$ (Alfa) & 2,14 \\
$\beta$ (Beta) & 0,43 \\
$\gamma$ (Gama) & 2,95 \\
$\delta$ (Delta) & 0,56 \\
\hline
\end{tabular}

Tabela 5. Concentração de minerais nos flocos de quinoa em comparação com outros cereais.

\begin{tabular}{lcccc}
$\begin{array}{c}\text { Minerais } \\
\left(\mathbf{m g . 1 0 0} \mathbf{~ g}^{-\mathbf{1}} \text { ) }\right.\end{array}$ & $\begin{array}{c}\text { Flocos de } \\
\text { quinoa }\end{array}$ & Arroz $^{\mathbf{1}}$ & Trigo $^{\mathbf{1}}$ & Aveia $^{\mathbf{1}}$ \\
Cálcio & 22,10 & 23 & 48 & 50 \\
Ferro & 6,52 & 1,5 & 4,6 & 3,81 \\
Fósforo & 421,95 & 333 & 387 & 450 \\
Zinco & 0,57 & 2,0 & 3,3 & 3 \\
Sódio & 25 & 7,0 & 4 & 4 \\
\hline
\end{tabular}

Fonte: ${ }^{1}$ León e Rosell (2007).

$210 \mathrm{mg}$ de fósforo.100 $\mathrm{g}^{-1}$ de flocos) e ferro (mínimo 4,2 mg de ferro.100 $\mathrm{g}^{-1}$ de flocos); diversamente, em relação ao sódio, satisfazem ao atributo "muito baixo" (máximo de $40 \mathrm{mg}$ de sódio. $100 \mathrm{~g}^{-1}$ de flocos) (BRASIL, 1998a, 2005). Os cereais, em geral, apresentam 70-75\% de fósforo como ácido fítico, formando quelatos com íons bivalentes evitando que o fósforo seja absorvido no trato gastrintestinal. No entanto, os cereais contêm a enzima fitase, que hidrolisa o ácido fítico transformando-o em inositol e ácido fosfórico livre (LEÓN e ROSELL, 2007).

O ferro presente na quinoa ocorre na forma não-heme, cuja absorção é de $2 \%$ a $5 \%$ em uma dieta mista. A absorção desse nutriente pode aumentar por meio do consumo de carnes, peixes e aves, em virtude do conteúdo de aminoácidos, como a cisteína, que se liga ao 
Análises químicas em flocos de quinoa: caracterização para a utilização em produtos alimentícios GEWEHR, M. F. et al.

ferro, aumentando sua absorção. Os polifenóis presentes, segundo Alvarez-Jubete et al. (2010) e Pásko et al. (2009), também podem diminuir a absorção desse mineral, uma vez que ocorre formação de complexos entre os grupos hidroxila dos compostos fenólicos e as moléculas de ferro (COZZOLINO, 1999).

\section{Conclusões}

Os flocos de quinoa apresentaram características nutricionais desejáveis em razão da quantidade e da variedade de nutrientes existentes. O teor de proteína juntamente com o equilíbrio de aminoácidos, com níveis semelhantes ou maiores, quando comparados com a indicação da FAO, destacaram o valor nutricional dessa semente.

Outros compostos, como fibras e lipídios, por causa do equilíbrio entre fibras solúveis e insolúveis, ácidos graxos insaturados e saturados, podem auxiliar na manutenção da saúde juntamente com os tocoferóis, ressaltando a importância do $\alpha$ e do $\gamma$-tocoferol.

Em relação aos minerais, destaca-se o alto teor de fósforo e ferro. Porém, serão necessários mais estudos para analisar a biodisponibilidade destes minerais.

A diversidade juntamente com a quantidade da composição de nutrientes nos flocos de quinoa podem auxiliar para se ter uma alimentação saudável e agregar valor na elaboração de produtos.

\section{Agradecimentos}

Agradecemos à Empresa Seven Boys, pelo suporte financeiro na realização das análises necessárias, e à UFRGS, pela Bolsa de Iniciação Científica (BIC).

\section{Referências}

ALONSO, N.; HIRS, C. H. W. Automation of sample application in amino acid analysers. Analytical Biochemistry, New York, v. 23, n. 5, p. 272-278, 1968. http://dx.doi.org/10.1016/00032697(68)90359-X

ALVAREZ-JUBETE, L.; WIJNGAARD, H.; ARENDT, E. K.; GALLAGHER, E. Polyphenol composition and in vitro antioxidant activity of amaranth, quinoa buckwheat and wheat as affected by sprouting and baking. Food Chemistry, London, v. 119, n. 2, p. 770-778, 2010. http://dx.doi.org/10.1016/j. foodchem.2009.07.032

ANGELIS, R. C. A importância dos ácidos graxos poliinsaturados. In: ANGELIS, R. C. Importância de Alimentos Vegetais na Proteção da Saúde. São Paulo: Atheneu, 2001. cap. 26, p. $145-147$

BHARGAVA, A.; SHUKLA, S.; OHRI, D. Chenopodium quinoa: an Indian perspective. Industrial Crops and Products,
Oxford, v. 23, n. 1, p. 73-87, 2006. http://dx.doi.org/10.1016/j. indcrop.2005.04.002

BRASIL. Ministério da Saúde. Secretaria de Vigilância Sanitária. Agência Nacional de Vigilância Sanitária. Portaria $n^{\circ} 27$, de 13 de janeiro de 1998. Regulamento Técnico referente à informação nutricional complementar. Diário Oficial da República Federativa do Brasil, Poder Executivo, Brasília, DF, 16 jan. 1998a. Disponível em: <http://e-legis.anvisa.gov. br/leisref/public/showAct. php?id=97\&wOrd=>. Acesso em: 28 dez. 2009.

BRASIL. Ministério da Saúde. Secretaria de Vigilância Sanitária. Agência Nacional de Vigilância Sanitária. Portaria $n^{\circ} 31$, de 13 de janeiro de 1998. Regulamento Técnico referente a alimentos adicionados de nutrientes essenciais. Diário Oficial da República Federativa do Brasil, Poder Executivo, Brasília, DF, jan. 1998b. Disponível em: <http://e-legis.anvisa.gov.br/leisref/ public/showAct. php?id=64\&word=>. Acesso em: $28 \mathrm{dez}$. 2009.

BRASIL. Ministério da Saúde. Secretaria de Vigilância Sanitária. Agência Nacional de Vigilância Sanitária. Resolução RDC $n^{\circ} 360$, de 23 de dezembro de 2003. Regulamento técnico sobre rotulagem nutricional de alimentos embalados, tornando obrigatória a rotulagem nutricional. Diário Oficial da República Federativa do Brasil, Poder Executivo, Brasília, DF, 26 dez. 2003. Disponível em: <http://e-legis.anvisa.gov.br/ leisref/public/showAct. php?id=9059\&word=>. Acesso em: 28 dez. 2009.

BRASIL. Ministério da Saúde. Secretaria de Vigilância Sanitária. Agência Nacional de Vigilância Sanitária. Resolução RDC $n^{\circ} 269$, de 22 de setembro de 2005. Regulamento técnico sobre a ingestão diária recomendada (IDR) de proteína, vitaminas e minerais. Diário Oficial da República Federativa do Brasil, Poder Executivo, Brasília, DF, 23 set. 2005. Disponível em: <http://e-legis.anvisa.gov.br/leisref /public/showAct. php?id=18828\&word=>. Acesso em: 28 dez. 2009.

COMAI, S.; BERTAZZO, A.; BAILONI, L.; ZANCATO, M.; COSTA, C. V. L.; ALLEGRI, G. The content of proteic and nonproteic (free and protein-bound) tryptophan in quinoa and cereal flours. Food Chemistry, London, v. 100, n. 4, p. 1350-1355, 2007. http:// dx.doi.org/10.1016/j.foodchem.2005.10.072

COZZOLINO, S. M. F. Fortificação de Alimentos versus biodisponibilidade. In: ANGELIS, R. C. Fome Oculta: Impacto Para a População do Brasil. São Paulo: Atheneu, 1999. cap. 30, p. 143-154.

CUNNIFF, P. A. (Ed.). Official Methods of Analysis of the Association of Official Analytical Chemists. 16th ed. Virginia: AOAC, 1995.

DINI, I.; TENORE, G. C.; DINI, A. Nutritional and antinutritional composition of Kancolla seeds: an interesting and underexploited andine food plant. Food Chemistry, London, v. 92, n. 1, p. 125-132, 2005. http://dx.doi.org/10.1016/j. foodchem.2004.07.008 
Análises químicas em flocos de quinoa: caracterização para a utilização em produtos alimentícios GEWEHR, M. F. et al.

DOGAN, H.; KARWE, M. V. Physicochemical properties of quinoa extrudates. Food Science and Technology International, London, v. 9, n. 2, p. 101-114, 2003. http://dx. doi. org/10.1177/1082013203009002006

FIRESTONE, D. (Ed.). Official Methods and Recommended Practices of the American Oil Chemists Society. 5th. ed. Champaign: AOCS, 1998. $1300 \mathrm{p}$.

GORINSTEIN, S.; LOJEK, A.; CÍZ, M.; PAWELZIK, E.; DELGADOLICON, E.; MEDINA, O. J.; MORENO, M.; SALAS, I. A.; GOSHEV, I. Comparison of composition and antioxidant capacity of some cereals and pseudocereals. International Journal of Food Science and Technology, Oxford, v. 43, n. 3, p. 629-637, 2008. http://dx.doi.org/10.1111/j.1365-2621.2007.01498.x

GORINSTEIN, S.; VARGAS, O. J. M.; JARAMILLO, N. O.; SALAS, I. A.; AYALA, A. L. M.; ARANCIBIA-AVILA, P.; TOLEDO, F.; KATRICH, E.; TRAKHTENBERG, S. The total polyphenols and the antioxidant potentials of some selected cereals and pseudocereals. European Food Research and Technology, Berlin, v. 225, n. 3-4, p. 321-328, 2007. http://dx.doi.org/10.1007/ s00217-006-0417-7

HARTMAN, L.; LAGO, R. C. A. Rapid preparation of fatty acid methyl esters from lipids. Laboratory Practive, London, v. 22 , n. 8, p. 475-476, 1973

HOLLAND, B.; WELCH, A. A.; UNWIN, I. D.; BUSS, D. H.; PAUL, A. A.; SOUTHGATE, D. A. T. The Composition of Foods: Me Cance and Widdowson's. 5th ed. London: Royal Society of Chemistry, 1998. 462 p.

HORWITZ, W. (Ed.). Official Methods of Analysis of the Association of Official Analytical Chemists. 13th ed. Washington: AOAC, 1980. $384 \mathrm{p}$

HORWITZ, W. (Ed.). Official Methods of Analysis of the Association of Official Analytical Chemists. 17th ed. Gaithersburg: AOAC, 2000. v. 2, p. 20-24.

HORWITZ, W. (Ed.). Official Methods of Analysis of the Association of Official Analytical Chemists. 18th ed. Arlington: AOAC, 2005.

IMPROTA, F.; KELLEMS, R. O. Comparison of raw, washed and polished quinoa (chenopodium quinoa willd.) to wheat, sorghum or maize based diets on growth and survival of broiler chicks. Livestock Research for Rural Development, Cali, v. 13, n. 1, 2001. Disponível em: <http://www.Irrd.org//rrd13/1/impr131. htm>. Acesso em: 28 dez. 2009.

INSTITUTO ADOLFO LUTZ - IAL. Normas Analíticas do Instituto Adolfo Lutz: Métodos Químicos e Físicos para Análise de Alimentos. 3. ed. São Paulo: IAL, 1985. v. 1, 533 p.

KARYOTIS, T.; ILIADIS, C.; NOULAS, C.; MITSIBONAS, T. Preliminary Research on Seed Production and Nutrient Content for Certain Quinoa Varieties in a Saline-Sodic Soil. Journal of Agronomy and Crop Science, Berlin, v. 189, n. 6, p. 402-408, 2003. http://dx.doi.org/10.1046/j.09312250.2003.00063.x

KONISHI, Y.; HIRANO, S.; TSUBOI, H.; WADA, M. Distribution of minerals in quinoa (Chenopodium quinoa Willd.) seeds. Bioscience Biotechnology and Biochemistry, Tokyo, v. 68, n. 1, p. 231-234, 2004. http://dx.doi.org/10.1271/bbb.68.231

KOZIOL, M. J. Chemical composition and nutritional evaluation of quinoa (chenopodium quinoa willd.). Journal of Food Composition and Analysis, San Diego, v. 5, n. 1, p. 35-68, 1992. http://dx.doi.org/10.1016/0889-1575(92)90006-6

LEÓN, A. E.; ROSELL, C. M. De Tales Harinas, Tales Panes: Granos, Harinas y Productos de Panificación en Iberoamérica. Córdoba: Hugo Báez Editor, 2007. 478 p.

LUCAS, B.; SOTELO, A. Effect of different alkalies, temperatures and hydrolysis times on tryptophan determination of pure proteins and foods. Analytical Biochemistry, New York, v.109, n. 1, p. 192-197, 1980. http://dx.doi.org/10.1016/00032697(80)90028-7

MADL, T.; STERK, H. MITTELBACH, M. Tandem Mass Spectrometric Analysis of a Complex Triterpene Saponin Mixture of Chenopodium quinoa. Journal of the American Society for Mass Spectrometry, New York, v. 17, n. 6, p. 795-806, 2006. http://dx.doi.org/10.1016/j.jasms.2006.02.013

NSIMBA, R. Y.; KIKUZAKI, H.; KONISHI, Y. Antioxidant activity of various extracts and fractions of Chenopodium quinoa and Amaranthus spp. Seeds. Food Chemistry, London, v. 106, n. 2, p. 760-766, 2008. http://dx.doi.org/10.1016/j. foodchem.2007.06.004

PÁSKO, P.; BARTON, H.; ZAGRODZKI, P.; GORINSTEIN, S.; FOLTA, M.; ZACHWIEJA, Z. Anthocyanins, total polyphenols and antioxidant activity in amaranth and quinoa seeds and sprouts during their growth. Food Chemistry, London, v. 115, n. 3, p. 994-998, 2009. http://dx.doi.org/10.1016/j. foodchem.2009.01.037

PIMENTEL, C. V. M. B.; FRANCKI, V. M.; GOLLÜCKE, A. P. B. Alimentos Funcionais: Introdução às Principais Substâncias Bioativas em Alimentos. São Paulo: Livraria Varela, 2005. 95 p.

RANHOTRA, G. S.; GELROTH, J. A.; GLASER, B. K.; LORENZ, K. J.; JOHNSON, D. L. Composition and protein nutritional quality of quinoa. Cereal Chemistry, Saint Paul, v. 70, n. 3, p. 303-305, 1993.

REPO-CARRASCO, R.; ESPINOZA, C.; JACOBSEN, S. $E$. Nutritional value and use of the Andean crops quinoa (Chenopodium quinoa) and kaniwa (Chenopodium pallidicaule). Food Reviews International, New York, v. 19, n. 1-2, p. 179-189, 2003

SALINAS, R. D. Alimentos e Nutrição: Introdução à Bromatologia. 3. ed. Porto Alegre: Artmed, 2002. 280 p. 
Análises químicas em flocos de quinoa: caracterização para a utilização em produtos alimentícios GEWEHR, M. F. et al.

SANTOS, K. M. O.; AQUINO, R. C. Grupos dos óleos e gorduras. In: PHILIPPI, S. T. Pirâmide dos Alimentos: Fundamentos Básicos da Nutrição. Barueri: Manole, 2008. cap. 7, p. 241-292. SCHOENLECHNER, R.; SIEBENHANDL, S.; BERGHOFER, E. Pseudocereals. In: ARENDT, E. K.; BELLO, F. D. Gluten-Free Cereal Products and Beverages. London: Food Science and Technology International, 2008. cap. 7, p. 149-190. Series.

SGARBIERI, V. C. Alimentação e Nutrição: Fator de Saúde e Desenvolvimento. São Paulo: Almed, 1987. 387 p.

SHUMACHER, A. B. Desenvolvimento de um Chocolate Meio Amargo com Maior Percentual de Proteína. 2008. 54 f. Dissertação (Mestrado em Ciência e Tecnologia de Alimentos)Faculdade de Engenharia de Alimentos, Universidade Federal do Rio Grande do Sul, Porto Alegre, 2008.
SPACKMAN, D. H.; STEIN, W. H.; MOORE, S. Automatic recording apparatus for use in the chromatography of amino acids. Analytical Chemistry, Washington, v. 30, n. 7, p.11901206, 1963. http://dx.doi.org/10.1021/ac60139a006

WORLD HEALTH ORGANIZATION - WHO. Protein and Amino Acid Requeriments in Humam Nutrition: Report of Join FAO/WHO/UNU Expert Consultation. Geneve: FAO/ WHO/UNU, 2002. 265 p. (Who Technical Report Series, 935). Disponível em: <http://whqlibdoc.who.int/trs/WHO_TRS_935_ eng.pdf>. Acesso em: 18 dez. 2009.

WRIGHT, K. H.; PIKE, O. A.; FAIRBANKS, D. J.; HUBER, C. S. Composition of atriplex hortensis, sweet and bitter chenopodium quinoa seeds. Journal of Food Science, Chicago, v. 67, n. 4, p. 1383-1385, 2002. http://dx.doi.org/10.1111/j.1365-2621.2002. tb10294.x 